\title{
REVISIÓN
}

\section{Cholesterol oxidized products in foods: potential health hazards and the role of antioxidants in prevention}

\author{
By Alfonso Valenzuela*, Julio Sanhueza and Susana Nieto \\ Laboratory of Lipids and Antioxidants, INTA, University of Chile, Santiago, Chile. P.O. Box 138-11, \\ Santiago, Chile. E-mail: avalenzu@uec.inta.uchile.cl
}

\section{RESUMEN}

Productos oxidados del colesterol en alimentos: riesgos potenciales para la salud y papel preventivo de los antioxidantes.

El colesterol es una molécula con un doble enlace en su estructura; por lo tanto es susceptible a la oxidación y su transformación en oxiesteroles. Estos productos de oxidación se encuentran en gran diversidad de alimentos y se forman durante la manufactura y procesamiento. Algunos de los oxiesteroles son potencialmente citotóxicos, mutagénicos, aterogénicos y carcinogénicos. Los huevos y productos derivados del huevo constituyen la principal fuente en la dieta de oxiesteroles. También se encuentran oxiesteroles en derivados lácteos y leche sometida a altas temperaturas. Carnes y patatas fritas y, en general, alimentos preparados mediante fritura con aceites vegetales/animales, son otra fuente de oxiesteroles de particular importancia en la dieta occidental. Con la intención de prevenir o reducir la oxidación del colesterol se utilizan antioxidantes sintéticos o de origen natural. Los antioxidantes no solo inhiben la oxidación de los ácidos grasos en los triglicéridos, sino que también pueden inhibir la oxidación de colesterol. Entre los antioxidantes sintéticos, 2,6-di-terciaributil-4metilfenol $(\mathrm{BHT})$ y terciari butilhidroquinona (TBHQ) pueden inhibir la oxidación térmica del colesterol. Entre los antioxidantes naturales, alfa- y gamma-tocoferol, extractos de romero, y el flavonoide quercetina, son potentes inhibidores de la oxidación del colesterol.

PALABRAS-CLAVE: Colesterol - Oxidación del colesterol Oxiesteroles - Antioxidantes sintéticos - Antioxidantes naturales

\section{SUMMARY}

Cholesterol oxidized products in foods: potential health hazards and the role of antioxidants in prevention.

Cholesterol is a molecule with a double bond in its structure, and therefore it is susceptible to oxidation leading to the formation of oxysterols. These oxidation products are found in many commonly consumed foods and are formed during their manufacture and/or processing. Concern about the consumption of oxysterols arises from the potentially cytotoxic, mutagenic, atherogenic, and possibly carcinogenic effects of some of them. Eggs and egg-derived products are the main dietary sources of oxysterols. Thermally processed milk and milk-derived products are also another source of oxysterols in our diet. Fried meats, and other miscellaneous foods, such as French fried potatoes, when prepared using vegetable/animal frying oil, are another important source of oxysterols in the western diet. Efforts to prevent or to reduce cholesterol oxidation are directed to the application of antioxidants of either synthetic or natural origin. Antioxidants cannot only inhibit triglyceride oxidation, but some of them can also inhibit cholesterol oxidation. Among synthetic antioxidants, 2,6-di-tertiarybutyl-4-methylphenol (BHT) and tertiary butylhydroquinone (TBHQ), can efficiently inhibit the thermal-induced oxidation of cholesterol. Among natural antioxidants, alpha- and gamma-tocopherol, rosemary extracts, and flavonoid quercetin, show the strongest inhibitory action against cholesterol oxidation.

KEY-WORDS: Cholesterol - Natural antioxidants - Oxidation - Oxysterols - Synthetic antioxidants.

\section{BIOLOGICAL IMPORTANCE OF CHOLESTEROL}

Steroid cholesterol (cholest-5-en- $\beta$-ol) is an essential metabolite required for important biological functions, such as cell membrane structure, where the steroid forms, together with phospholipid molecules, the integral part of the lipid bilayer (Spector \& Yorek, 1985). Cholesterol inserts into bilayers with its long axis perpendicular to the plane of the membrane, preventing the crystalization of fatty acyl chains by fitting itself between them (Yeagle, 1985). Cholesterol also provides the structural scaffolding for the synthesis of steroids and steroid hormones, and for the biosynthesis of bile and bile acid salts. Sterol also plays an important role in embryonic development (Roux et al., 2000). Organisms obtain cholesterol through biosynthesis and diet. Cholesterol biosynthesis is a highly regulated process that occurs in almost all animal tissues, but in higher mammals the liver, the adrenal gland, and the ovarian and testis show the most important biosynthetic activity. Bile is the major excretion route of cholesterol from the body, predominantly as unesterified cholesterol (Robins \& Brunengraber, 1982). In the adult human approximately $400 \mathrm{mg}$ of cholesterol per day are converted to bile acids and only approximately $50 \mathrm{mg}$ are converted to hormones (Ishibashi et al., 1996).

\section{CHOLESTEROL AUTOXIDATION AND OXIDATION}

Cholesterol is a molecule with an unsaturated bond at position 5-6 of the sterol nucleus, and therefore it is prone to oxidation (Maerker, 1987). The molecule 
undergoes autoxidation by a free-radical mechanism leading to the formation of hydroperoxides and then to a number of oxidation products, the so-called oxysterols. These oxidation products are a group of sterols similar in structure to cholesterol, but which contain an additional oxygen function such as a hydroxyl group, ketone group, or an epoxide group at the sterol nucleus or at the side chain of the molecule. Many different oxysterols (up to 70) have been identified (Schroepfer, 2000), and it is likely that many remain to be identified. The physical state of cholesterol greatly influences the types of oxidation products. The autoxidation of solid cholesterol has been extensively studied and is well-documented (Korahani et al., 1982). When cholesterol is in its crystalline state and in the presence of air, the oxidation reaction is governed by the arrangement of molecules in the crystal. Cholesterol molecules are arranged in double layers with the 3-hydroxyl groups in juxtaposition and side chain exposed.

The oxidation of cholesterol may be initiated by polyunsaturated fatty acid oxidation (Kubow, 1993). An interaction of triglycerides with cholesterol may accelerate the oxidation of the sterol, and cholesterol may also influence triglyceride oxidation (Kim \& Nawar, 1991). The peroxides formed on polyunsaturated fatty acids during lipid oxidation may substract hydrogen from the $\Delta 5-6$ double bond allowing the formation of a free radical into the cholesterol structure (Paniangvait et al., 1995). This free radical may migrate to the position 4 or 7 of ring $A$ and $B$ respectively, allowing the reaction of molecular oxygen at the position 4, 5, 6 or 7 . However, the most favored and stable position is at carbon 7, where the hydroperoxide formed, may form either a hydroxyl derivative by decomposition (7 $\alpha$-hydroxycholesterol or $7 \beta$-hydroxycholesterol), or a keto-derivative by dehydration (7-ketocholesterol). Another possibility is the reaction of the molecular oxygen free radical directly with the double bond, forming by addition a 5,6-epoxycholesterol, which through further dehydration can be transformed to a triol (cholestane- $3 \beta, 5 \alpha, 6 \beta$-triol). Oxidation at the lateral chain may produce either the 20-hydroxy- or the 25-hydroxycholesterol derivative. Oxygen free-radicals show different behavior as inductors of cholesterol oxidation. While the superoxide free-radical proves ineffective in inducing oxidation, the presence of the free radical together with hydrogen peroxide, the product of the dismutation of the superoxide free-radical, exerts a strong pro-oxidative effect (Lee et al., 1977). This means that hydroxyl free-radicals formed from the reaction of superoxide with hydrogen peroxide may be involved in the oxidation mechanism (Sevanian \& McLeod, 1987). The structures of the main oxysterols, which can be identified in traditional western foods, are depicted in figure 1.

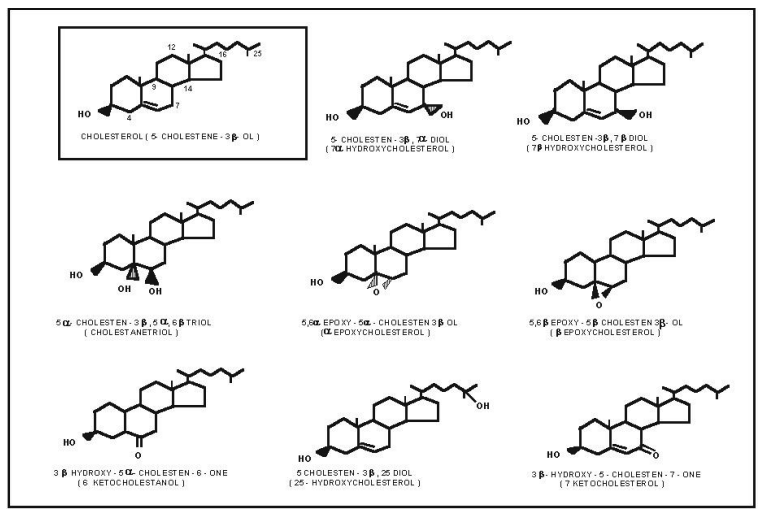

Figura 1

Main cholesterol oxides (oxysterol)

\section{ANALYTICAL PROCEDURES TO EVALUATE OXYSTEROLS}

Due to the presence of low concentrations (ppm or ppb) of oxysterols in foods or in animal tissue, isolation procedures, which separate the sterol oxidation products from other interfering substances, and quantification of oxysterols, are difficult analytical problems. Usually these procedures involve two steps: a.- Separation of the sterol fraction from other lipid materials, followed by b.Removal of cholesterol. The initial separation can be accomplished either by saponification-extraction, or by column chromatography on silica (Park \& Addis, 1992). This must be followed by thin-layer or reversed-phase column chromatography to remove cholesterol that would interfere with the subsequent analyses. Previous workers in the field have employed saponification of the extracted lipids with hot alkali as an important part of the enrichment procedure. This step frees the bulk of the lipids from the sterol residue and converts esterified cholesterol to the free sterol. Nevertheless, some important cholesterol oxides, notably 7-ketocholesterol, have long been known to be unstable to hot, aqueous alkali. The artifactual formation of cholesterol oxidation products during the course of the hot saponification procedure has also been reported (Park \& Addis, 1992). Cold saponification may avoid these troubles, and is now the standard procedure for the extraction of oxysterols before analytical separation (Park \& Addis, 1985; Zhang et al., 1992).

Analytical procedures for the determination of the extent of cholesterol oxidation in food, especially in heated and/or stored foods having a high cholesterol content, include capillary gas-chromatography (GC) (Addis et al., 1989; García \& Maraschielo, 1997), GC-mass spectrometry (GC-MS) (Park \& Addis, 1986; Osada et al., 1993), and high performance liquid chromatography (HPLC) (Park \& Addis, 1985ª). Several researchers have used GC because it allows the rapid separation and identification of up to 17 
different oxysterols. The procedure requires the previous derivatization of the sterols with hexamethyl trichloro methylsilane to form the silyl-esters. To confirm identification by GC, equipment can be coupled to an MS. Taking into account that HPLC greatly simplifies the quantification procedure and introduces fewer artifacts, normal phase (NP), and reversed-phase (RP) methods have been applied to the separation of oxysterols by several researchers (Park \& Addis, 1985; Park \& Addis, 1992; Smith, 1996). In general NP-liquid chromatography systems proved to be more effective than RP, but full resolution over the entire polarity range of oxidation products was not achieved (Park \& Addis, 1985). Particle beam HPLC-MS is also another analytical alternative for the detection of oxysterols at the nanograms levels and has been successfully applied by Careri et al. (1998). The excellent revisions of Park \& Addis (1992) and Schroepfer (2000) summarize the main analytical procedures for assessing cholesterol oxides in lipid samples.

\section{OXYSTEROLS IN COMMONLY CONSUMED FOODS}

It has been estimated that approx. $1 \%$ of the cholesterol consumed in a mixed western diet is oxidized cholesterol (van de Bovenkamp et al., 1988). Dietary sources of oxysterols are cholesterol-rich foods, such as dairy, processed eggs, and meat products. Cholesterol containing foods, when subjected to high temperatures during manufacturing and/or processing may form variable amounts of oxysterols depending on the analytical method applied to their identification, as was discussed above. The most commonly detected oxysterols in foods are the major products of cholesterol oxidation: $7 \alpha$-hydroxycholesterol, $7 \quad \beta$-hydroxycholesterol, $\alpha$-epoxycholesterol, $\beta$-epoxycholesterol, and 7-ketocholesterol, which can be found in amounts ranging from ng to $\mathrm{mg}$ per $\mathrm{g}$ of sample (Sander et al., 1989; Paniangvait, et al., 1995).

\section{Eggs and egg-derived products}

Foods which are naturally characterized by their high cholesterol content are important sources of oxysterols when processed, such as eggs and egg-derived products. An average egg contains 200-220 mg cholesterol, which is about twice the cholesterol content of butter and freeze-dried meat products, and about 5-10 times more cholesterol than is found in most dairy products. Dried whole egg, or dried egg yolk, but not fresh egg yolk, are important sources of oxysterols when used for the manufacturing of convenience foods (Missler et al., 1985). The oxysterol content of eggs (dehydrated, dried) are in the range of $0.05-1.50 \mu \mathrm{g} / \mathrm{g}$, and for eggs-yolk (dehydrated or dried) amounts are 15-120
$\% \mathrm{~g} / \mathrm{g}$ (Morgan \& Armstrong, 1992). The irradiation applied to the control of Salmonella considerably increases the amount of oxysterols in egg yolk powder from $10 \mu \mathrm{g} / \mathrm{g}$ to $470 \% \mathrm{~g} / \mathrm{g}$ on average (Du \& Ahn, 2000).

\section{Dairy products}

Milk powder and several other dairy products are reported to contain oxidized cholesterol after processing (Dionisi et al., 1998). Oxysterols found in these products are the same as those found in processed eggs. However, fresh milk contains none or only trace amounts of cholesterol oxides, which means that processing (e.g. high temperature) is the main source of oxysterols (Angulo et al., 1997). Other milk-derived products such as cheeses, yogurt, and evaporated milk, contain very low amounts of cholesterol oxides. The oxysterol content of milk powder is in the range $1.0-2.5 \mu \mathrm{g} / \mathrm{g}$. For dehydrated cheese, 8-15 $\mu \mathrm{g} / \mathrm{g}$; for skimmed milk powder, $0.01-0.1 \mu \mathrm{g} / \mathrm{g}$; and for hole milk powder, $0.2-0.8 \mu \mathrm{g} / \mathrm{g}$ (Paniangvait et al., 1995). The amount of oxysterols present in these products depends on the processing temperature, and on the storage period (Nourooz-Zadeh \& Appelqvist, 1988).

\section{Meat and meat-derived products}

The mean lipid content of lean meat is $10 \%$, wet weight basis, of which triglycerides and phospholipids are major components and cholesterol is a lesser component, ranging from 50 to $89 \mathrm{mg} \%$. The main source of oxysterols in meats (from bovine, birds and porcine origin) is heat processing, mainly over-heating. Fresh meat and fresh meat products contain none or trace amounts of cholesterol oxides. Oxysterols contained in cooked meat are from 180-1900 $\mu \mathrm{g} / \mathrm{g}$ (Paniangvait et al., 1995).

\section{Other food products}

It has been proposed that the frying process in animal/vegetable oils is an important source of oxysterol in the western diet. The main targets are French fried potatoes, which together with other deep-fried foods cooked in animal/vegetable fat are considered the main source of oxysterols in the USA and Latin America. The oxysterol content of French potatoes fried in tallow or vegetable/animal oil may be in the range of $1.4 \mathrm{mg} / \mathrm{g}$ to $16.7 \mathrm{mg} / \mathrm{g}$, depending on the origin and/or the animal fat content of the frying oil (Paniangvait et al., 1995).

\section{ABSORPTION AND BIOLOGICAL EFFECTS OF OXYSTEROLS}

Oxysterols that are on average more polar than cholesterol may also be absorbed into the intestinal 
track by a mechanism similar to cholesterol (Emmanuel et al., 1991). That is, oxysterols may form a structural part of the mixed micelles at the small intestinal lumen. Oxysterols may enter the blood circulation together with dietary cholesterol and biliary cholesterol (endogenous cholesterol) as part of chylomicron structure (Linseisen \& Wolfran, 1998). Because of the similarity in structure between oxysterols and cholesterol, it has been long assumed that their transport in serum would be similar (Peng et al., 1985). Oxysterols, such as cholesterol, are also transported by low-density lipoproteins (LDL), and there is evidence that high-density lipoproteins (HDL), which perform reverse cholesterol transport, are also involved in the transport of oxysterols from the tissue to the liver (Streuli et al., 1981; Robins \& Fasulo, 1997). Although a major fraction of oxysterols is from dietary sources, it has been proposed that some amount of the circulating oxysterols may be formed from lipoprotein oxidation in the blood stream and/or in the intracellular metabolism (Linseisen et al., 1998). Oxysterol may also be formed by intracellular enzymatic reactions. Parenchymal hepatocytes have been thought to be the primary, if not the sole, cell type possessing a functional enzyme system that could convert cholesterol into oxidized derivatives, namely the cytochrome P-450 system (Boström, 1994). Within the cytochrome P-450 family, 27-hydroxylase activity is an important enzyme responsible for the hydroxylation of the cholesterol side-chain (Cali \& Russell, 1991). Available data suggest that enzymatically generated oxysterols may account for a significant percentage of oxysterols found in serum and other tissues (Linseisen et al., 1998 ${ }^{\mathrm{a}}$ ).

\section{REGULATORY FUNCTIONS OF OXYSTEROLS AT CELLULAR LEVEL}

Oxysterols are considered cytotoxic (Leland \& Johnson, 1989), although some researchers have postulated regulatory functions for some oxysterols at the intracellular level (Luu \& Moog, 1991; Lund \& Björkhem, 1995). 3-Hydroxy-3-methylglutaryl coenzyme A (HMG-CoA) reductase, the enzyme catalyzing the rate-limiting step in cholesterol biosynthesis, is among the most highly regulated enzyme in nature. Many oxysterols are potent competitive inhibitors of HMG-CoA reductase at concentration levels below 100 nM (Tanaka et al., 1983). However, the regulatory action of oxysterols on the enzyme is extended not only to its activity, but also to its expression at a genetic level. Oxysterols are capable of inhibiting the synthesis of HMG-CoA reductase at the transcriptional level by decreasing the reductase $\mathrm{mRNA}$ and the rate of protein synthesis, and at the post-transcriptional level by modifying the anchoring of the enzyme at the smooth endoplasmatic reticulum membrane (Edwards \&
Ericsson, 1999). Cholesterol biosynthesis is also regulated by transcription factors named steroid regulatory element binding proteins (Brown \& Goldstein, 1997). A newly discovered transcription factor, identified as LXR (Björkhen \& Diczfalusy, 2002), regulates the catabolic degradation of cholesterol by activation of the gene controlling cholesterol $7 \alpha$-hydroxylase, the rate-limiting enzyme in the formation of bile acids (Ishibashi et al., 1996). Oxysterols may bind to LXR and thereby induce transcription of cholesterol $7 \alpha$-hydroxylase, thus increasing the removal of cholesterol as bile acids (Lehmann et al., 1997).

Oxysterols are also potent regulators of intracellular cholesterol esterification (Brown et al., 1975). The membrane bound enzyme acetyl-CoA:cholesterol acyl transferase (ACAT), which is responsible for the intracellular esterification of cholesterol, is strongly activated by oxysterols (Saucier et al., 1985). Because cholesterol achieved comparable enhancement of ACAT only at much higher concentrations, it has been speculated that the true activators of the enzyme in mammalian cells are oxysterols rather than cholesterol by itself (Drevon et al., 1980). The modulation of ACAT activity is probably exerted at the post-translational level (Kushuhara et al., 1992).

\section{OXYSTEROLS AND ATHEROGENESIS}

The cytotoxic, mutagenic and probably carcinogenic effects described for some oxysterols have been observed in in vitro models. However, the atherogenic action of oxysterols has been demonstrated both, in vitro and in vivo study models, being the most well characterized pathological expression of cholesterol oxidation (Staprans et al., 1998; Leonarduzzi et al., 2002). Atherosclerotic lessions not only contain cholesterol, but also a series of oxysterols. In the widely accepted model for the pathogenesis of atherosclerosis, the impact of oxidatively modified low-density lipoprotein (LDL) particles is very important (Kumar \& Singhal, 1991; Brown \& Jessup, 1999). Besides polyunsaturated fatty acids and apolipoproteins, the cholesterol moiety of LDL can undergo oxidative damage, resulting in different effects on target cells (e.g. macrophages and aortic smooth muscle cells) that may promote the development of atherosclerosis (Chang et al., 1997). Oxidized LDL is potentially more atherogenic than native LDL in several ways: 1.- It is chemotactic for circulating monocytes; 2 .- It is an inhibitor of the motility of resident macrophages; 3.- It is cytotoxic for cell in culture; 4.- It can stimulate the release of a chemotactic factor from endotelial cells. Many of these oxidized LDL characteristics are attributed to the oxysterol content of the lipoprotein (Rong et al., 1999). In vivo oxysterols are formed either enzymatically or via autoxidation of 
cholesterol. Although it has not been established which is the most prevalent way to LDL-cholesterol oxidation in vivo, the contribution of free iron to oxidation (through non-enzymatically autoxidation) is considered important. The contribution of dietary oxysterols to the total amount of oxysterol measurable in plasma and lipoproteins of humans is still unclear.

\section{OXYSTEROL METABOLISM}

\section{Oxysterols and bile acid synthesis}

Most sterols, including cholesterol, are eliminated from the body through bile secretion. Synthesis of bile acids occurs in the liver through 7-hydroxylation of cholesterol; the oxysterol, 7-hydroxycholesterol, so formed can then be used to synthesize both cholic acid, the most common bile acid, and chemodeoxycholic acid (Morel \& Lin, 1996). It is generally accepted that the catabolism of oxysterols is similar to that of cholesterol. However, it is not clear whether oxysterols and cholesterol share the same pathways for bile acid synthesis. Nevertheless, it has been proposed that a family of P-450 7-hydroxylases isozymes catalyze oxysterol metabolism more independently than P-450 hydroxylases that catalyze cholesterol metabolism (Javitt, 1990).

\section{Oxysterols and steroidogenesis}

As with cholesterol, which serves as a precursor for many steroid hormones, there is evidence that oxysterols, especially those with a hydroxyl group on the side chain, can serve as substrates for steroid hormone synthesis in steroidogenic cells. Tuckey et al. (1992) demonstrated that hydroxycholesterol was comparable to cholesterol as a substrate for side chain cleavage.

\section{Esterification of oxysterols}

There is ample evidence that oxysterols are readily susceptible to esterification reaction. Fatty acid esters are the predominant form of oxysterols found in extrahepatic tissues such as the aorta (Bjorkhem, 1992), and these esters are also found in plasma associated with various lipoproteins (Peng et al., 1985). Using purified lecithin:cholesterol acyltransferase (LCAT), the enzyme responsible for esterification of cholesterol in serum, or the non-lipoprotein fraction of serum as a source for the enzyme, studies in vitro have shown that oxysterols are readily esterified and that the esterification can be inhibited by agents known to inhibit the esterification of cholesterol (Lin \& Morel, 1996). Similarly, tissue culture studies have shown that oxysterols can be esterified by ACAT (Lichtenstein \& Brecher, 1983). Although oxysterols have an additional oxygen group that might be available for esterification, fatty acid monoester formation, most likely at 3-position of the sterol nucleus, appears to predominate (Lin \& Morel, 1996).

\section{INHIBITION OF OXYSTEROL FORMATION, THE ROLE OF ANTIOXIDANTS}

In light of the potentially dangerous effects of oxysterols for human health, efforts to prevent or to reduce oxysterol consumption are now currently made. As processed foods of animal origin are the main dietary sources of oxysterols, prevention of its formation during manufacturing, processing, storage, or culinary preparation, is of importance. Antioxidants, both of synthetic or natural origin, are widely applied to prevent lipid oxidation in processed foods, raw materials, or fats and oils used in manufacturing (Valenzuela \& Nieto, 1996). However, antioxidant action is directed to prevent or delay fatty acid oxidation. The effect of antioxidants to prevent oxysterol formation has been scarcely investigated.

Antioxidants are organic lipid- or water-soluble substances that can scavenge the active forms of oxygen involved in the initial steps of oxidation, or break the oxidative chain reaction. Antioxidants may react with the fatty acid peroxy radicals to form stable antioxidant radicals, which are either too unreactive for further reactions or form non-radical products (Valenzuela \& Nieto, 1996). Most widely used synthetic antioxidants in human foods are 2,6-ditertiarybutyl-4-methylphenol (BHT), tertiarybutyl4-hydroxyanisole (BHA), tertiary butylhydroquinone (TBHQ), and the n-propyl ester of 3,4,5trihydroxybenzoic acid (propyl gallate, PG) (Valenzuela et al., 2003). For animal feeding, 6-ethoxy-1,2-dihydro-2,4-trimethylquinoline is also used (ethoxyquine, EQ), which is not permitted for human consumption. These synthetic antioxidants have been used for a long time, although recently some concerns have been raised due to the possible potential toxicity in some of them (Lachance et al., 2001). Natural antioxidants, which are present in variable amounts in vegetables such as fruits, leafy greens, flowers, roots, grains, and seeds, have gained prominence as alternatives to synthetic antioxidants (Aruoma, 1997). Research interest in the properties and occurrence of natural antioxidants center upon vitamin E (mainly the alpha, beta, and gamma tocopherol homologous), some herbs extracts, such as rosemary extract, carotenoids, and various flavonoids (Valenzuela, 2002; Valenzuela et al., 2003).

Since cholesterol oxidation proceeds via a free radical mechanism, similar to polyunsaturated fatty acid oxidation (Kubow, 1993), antioxidants used to inhibit general fat and oil oxidation are also able to prevent or retard cholesterol oxidation. However, results are diverse and sometimes contradictory. 
Morgan \& Armstrong (1992) demonstrated that BHT, $B H A$, and $P G$ were slightly effective in slowing hydrogen peroxide-induced cholesterol oxidation in egg yolk during spray drying. Huber et al. (1995) showed a significant inhibitory effect of BHA on oxysterol formation when spray-dried egg yolk oxidation is catalyzed by $\mathrm{Cu}^{2+}$ during accelerated storage at $60{ }^{\circ} \mathrm{C}$. Maerker \& Unruh (1986) observed that $\mathrm{BHT}$ is unable to inhibit cholesterol oxidation during hotsaponification oftriglycerides. Thesame antioxidant cannotinhibitoxysterol formation from irradiated egg yolk powder (Morgan \& Armstrong, 1992). The effect of the synthetic antioxidants $B H T$, $B H A, T B H Q, P G$ and $E Q$, on cholesterol oxidation using a vegetable oil as substrate for oxidation and monitored under the Rancimat 679 test conditions was recently communicated (Valenzuela et al., 2002). BHT and TBHQ behave as the most effective inhibitors, BHA and EQ being less effective, and PG beingunabletoinhibitcholesteroloxidation.

Tocopherols, in addition to possessing the vitamin $E$ function, are the major natural antioxidants in foods and are important for the stability of vegetable oils (Valenzuela \& Nieto, 1996). This antioxidant aspect of tocopherol chemistry has been extensively studied, especially regarding the relative antioxidant activity of $\alpha$-tocopherol, and less extensively for the $\gamma$-, and $\delta$-tocopherol homologues. While some researchers claim that $\gamma$-tocopherol is a better antioxidant than $\alpha$-tocopherol (Pokorny, 1991; Lampi et al., 1999), other researchers reported a better effectiveness of $\alpha$-tocopherol as antioxidant (Yoshida at al., 1993). Differences are probably due to the different oxidation models used to assess the antioxidant activity of these tocopherols. It is generally accepted that $\alpha$-tocopherol has a higher ability for hydrogen donation than its $\gamma$-homologue. The later was often found to be a better antioxidant in pure liquid-phase systems especially when comparison was made using high concentrations. The antioxidant effect of $\alpha$-tocopherol against cholesterol oxidation has been studied in models of diverse complexity, such as spray-dried egg yolk, fish oil, sunflower oil, and palm oil (Li et al., 1996), or dehydrated and powdered anchovy (Shozen et al., 1997). For all these models, $\alpha$-tocopherol has been identified as the most effective antioxidant, with better activity than other antioxidants, such as BHA or BHT. Csallany et al. (2002) have recently demonstrated that $\alpha$-tocopherol, BHA, and BHT can inhibit the oxidation of cholesterol in the presence of superoxide anion, water, and hydrogen peroxide. In an in vivo model, Galobart et al. (2002) demonstrated that feeding laying hens with linseed oil or sunflower oil added with $\alpha$-tocopheryl acetate may reduce cholesterol oxidation of spray-dried omega-6/ omega-3 fatty acid-enriched eggs during storage. The effect of $\alpha-, \beta-, \gamma-$, and $\delta$-tocopherol on cholesterol-containing liposomes, when fatty acid and cholesterol oxidation is induced by $\mathrm{Fe}^{2+}$, was recently communicated (Valenzuela et al., 2002 ${ }^{\mathrm{a}}$ ). In these conditions, tocopherols exhibit a different antioxidant effect. $\gamma$-Tocopherol behaves as the strongest antioxidant, followed by $\alpha$-tocopherol. $\delta$-Tocopherol and $\beta$-tocopherol are devoid of antioxidant activity. Tocopherols having antioxidant activity show as more efficient to inhibit oxysterol formation at the lateral chain of cholesterol (e.g. inhibition of $20-\mathrm{OH}$ and $25-\mathrm{OH}$ ) than at the nucleus of the sterol (e.g. 7 alpha-OH, 7 beta-OH, 5 alpha-3OH and 7-keto) (Valenzuela et al., 2002 ${ }^{a}$ ).

Rosemary extract is a food grade natural antioxidant oleoresin obtained from the leaves of the evergreen shrub rosemay (Rosmarinus officinalis. $L$ ) (Okamura et al., 1994). The extract contains four effective antioxidants: carnosol, rosmanol, isorosmanol, and rosemarydiphenol (Wu et al., 1982). These four compounds are odorless and tasteless diterpenolactones when processed, and among these lactones, rosmarydiphenol and rosmanol, show antioxidant activity stronger than $\mathrm{BHA}$ and BHT. The effect of rosemary extract on cholesterol oxidation was recently tested using highly purified soybean oil as the substrate for oxidation. In these experimental conditions, rosemary extract exerts a strong antioxidant effect by preventing both soybean oil oxidation and cholesterol oxidation (Valenzuela et al., 2004).

Flavonoids comprise a well-known family of natural substances that exhibit antioxidant properties (Cook \& Samman, 1996). These structures are ubiquitous in photosynthesizing cells, seeds, fruits, pollen, and flowers (Havsteen, 1983). Flavonoids have been defined as "high level" antioxidants (Robak \& Gruyglewski, 1988). That is, they act by scavenging those free radicals or exited forms of oxygen involved in the first stages of lipid oxidation, such as the singlet oxygen, the superoxide free radical or the hydroxyl free radical (Fraga et al., 1987). The effectiveness of some flavonoids as antioxidants for fats and oils has been previously demonstrated (Das \& Pereira, 1990; Nieto et al., 1993). The effect of four flavonoids (quercetin, catechin, morin, and rutin) was recently assayed against cholesterol oxidation when oxidation is induced by temperature, and using soybean oil as substrate for oxidation (Valenzuela et al., 2004). In these conditions, quercetin was highly effective to prevent cholesterol oxidation. Catechin, also showed protective action, but less efficiently than quercetin. The other two flavonoids, morin and rutin, were devoid of antioxidant activity. The literature does not describe any assay of cholesterol oxidation involving flavonoids as antioxidants; therefore, substances such as quercetin and catechin cannot be underestimated as future food grade antioxidants, 
and as inhibitors of temperature-induced cholesterol oxidation.

Information about the effect of natural antioxidants other than tocopherols on cholesterol oxidation is quite scarce. In the last two decades, interest in using natural ingredients in foods has increased dramatically. Many attempts have been made to replace synthetic antioxidants with natural products. The emphasis given to natural antioxidants results from concerns over the toxicity of some synthetic antioxidants and from the research findings, which point out a relationship between active dietary ingredients, like natural antioxidants, and their protection of cells from free radical-induced oxidative stress in the human body (Fitch-Haumann, 1990).

\section{CONCLUDING REMARKS}

Cholesterol oxidation products can by potentially harmful to human health. These products are formed from cholesterol-containing foods when processing, especially when high temperatures are applied during different stages of food manufacturing. Parallel to the identification of these cholesterol-oxidized products that can be dangerous, and of their actions at the cellular level, it is necessary to make an effort to prevent oxysterol formation during the different stages of food processing or into the raw materials used in its manufacturing. Antioxidants, both of synthetic or natural origin, may confer this protection. Some of them have demonstrated efficiency to inhibit cholesterol oxidation in different experimental models. However, more research must be carried-out to characterize the best way to apply antioxidants to prevent cholesterol oxidation. This is a challenge for biochemists, food chemists, food engineers, and processing technologists.

\section{ACKNOWLEDGMENTS}

The work of the authors is supported by FONDECYT, projects 1990759 and 1020720, and by Alltech Inc (USA).

\section{REFERENCES}

Addis, P. B., Emanuel, H., Bergmann, S., and Zavoral, J. (1989).-"Capillary GC quantification of cholesterol oxidation products in plasma lipoproteins of fasted humans".- Free Rad. Biol. Med. 7, 179-182.

Angulo, A. J., Romera, J. M., Ramírez, M., and Gil, A. (1997).-"Determination of cholesterol oxides in dairy products. Effect of storage conditions".- J. Agric. Food Chem. 45, 4318-4323.

Aruoma, O. I. (1997).- "Extracts as antioxidant prophylactic agents".- INFORM 8, 1236-1242.

Björkhem, ı. (1992).- "Mechanism of degradation of the steroid side-chain in the formation of bile acids". J. Lipid Res. 33, 455-471.
Björkhem, I., and Diczfalusy, U. (2002).-"Oxysterols, friends, foes, or just fellow passengers?".- Arterioscler. Thromb. Vasc. Biol. 22: 734-742.

Boström, H. (1994).-"Binding of cholesterol to cytochromes P-450 from rabbit liver microsomes".- J. Biol. Chem. 258, 15091-15094.

Brown, M. S., Dana, S. E., and Goldstein, J. L. (1975)-"Cholesterol ester formation in cultured human fibroblasts. Stimulation by oxygenated sterols".- J. Biol. Chem. 250, 4025-4027.

Brown, M. S., and Goldstein, J. L. (1997).- "The SREBP pathway: regulation of cholesterol metabolism by proteolysis of a membrane-bound transcription factor".- Cell 89, 331-340.

Brown, A. J., and Jessup, W. (1999).- "Oxysterols and atherogenesis".- Atherosclerosis 142, 1-28.

Cali, J. J., and Russell, D. W. (1991).-"Characterization of human sterol 27-hydroxylase . A mitochondrial cytochrome P-450 that catalyzes multiple oxidation reactions in bile acid biosynthesis".- J. Biol. Chem. 266, 7774-7778.

Careri, M., Ferretti, D., Manini, P., Musci, M. (1998)."Evaluation of particle beam high-performance liquid chromatography-mass spectroscopy for analysis of cholesterol oxides".- J. Chromatography A 794, 253-262.

Chang, Y. H., Abdalla. S. P., and Sevanian, A. (1997).-"Characterization of cholesterol oxidation products formed by oxidative modification of low density lipoproteins".- Free Radical Biol. Med. 23, 202-214.

Cook, N. C., and Samman, S. (1996).- "Flavonoidschemistry, metabolism, cardio-protective effects, and dietary sources".- Nutr. Biochem. 7, 66-76.

Csallany, A. S., Hee-Lee, J., and Shoeman, D. W. (2002)."Protection of superoxide-induced cholesterol oxidation by antioxidants in protic conditions".- Int. J. Food Sci. Nutr. 53, 403-409.

Das, N. P., Pereira, T. A. (1990).- "Effects of flavonoids on thermal autoxidation of palm oil: Structure-activity relationship".- J. Am. Oil Chem. Soc. 67, 255-258.

Dionisi, F., Golay, P. A., Aeschlimann, J. M., and Fay, B. (1998).-"Determination of cholesterol oxidation products in milk powders: methods comparison and validation".- J. Agric. Food Chem. 46, 2227-2233.

Drevon, C. A., Weinstein, D. B., and Steinberg, D. (1980)."Regulation of cholesterol esterification and biosynthesis in monolayer cultures of normal adult rat hepatocytes". J. Biol. Chem. 255, 9128-9137.

Du, M., and Ahn, D. U. (2000).- "Effects of antioxidants and packing on lipid and cholesterol oxidation and color changes of irradiated egg yolk powder".- J. Food Sci. 65, 625-629.

Edwards, P. A., and Ericsson, J. (1999).- "Sterol and isoprenoids: signaling molecules derived from the cholesterol biosynthetic pathway".- Ann. Rev. Biochem. 68, 157-185.

Emmanuel, H. A., Hassel, C. A., Addis, P. B., Bergmann, S. D., and Zavoral, J. H. (1991).- "Plasma cholesterol oxidation products (oxysterols) in human subjects fed a meal rich in oxysterols".- J. Food Sci. 56, 843-847.

Fitch-Haumann, B. (1990).- "Antioxidants. Firm seeking products they can label as natural". INFORM 1, 1002-1013.

Fraga, C., Martino, V., Ferraro, G., Coussio, J., and Boveris, A. (1987).- "Flavonoids as antioxidants evaluated by in vitro and in situ chemiluminescence".Biochem. Pharmacol. 36, 717-721.

Galobart, J., Guardiola, F., Barroeta, A. C., López-Ferrer, S., and Baucells, M. D. (2002).-"Influence of dietary 
supplementation with $\alpha$-tocopheryl acetate and canthaxantin on cholesterol oxidation in n-3 and n-6 fatty acid-enriched spray-dried eggs".- J. Food Sci. 67, 2460-2466.

García, J. A., and Maraschiello, C. (1997).- "Procedure for the determination of eight cholesterol oxides in poultry meat using column and solvent venting capillary gas chromatography".- J. Chromatography A.764, 279-293.

Havsteen, B. (1983).- "Flavonoids, a class of natural products of high pharmacological potency".- Biochem. Pharmacol. 32, 1141-1148.

Huber, K. C., Pike, O. A., Huber, C. S. (1995).- "Antioxidant inhibition of cholesterol oxidation in a spray-dried food system during accelerated storage".- J. Food Sci. 60, 909-916.

Ishibashi, S., Schwarz, M., Frykman, P. K., Herz, J., and Russell, D. W. (1996).- "Disruption of cholesterol 7 -hydroxylase gene in mice I: postnatal lethality reversed by bile acid and vitamin supplementation". $J$. Biol. Chem. 271, 18017-18023.

Javitt, N. B. (1990).- "26-hydroxycholesterol: synthesis, metabolism, and biological activities".- J. Lipid Res. 31, 1527-1533.

Kim, S. K., and Nawar, W. W. (1991).- "Oxidative interactions of cholesterol with triacylglycerides". J.Am. Oil Chem. Soc. 68, 931-934.

Korahani, V., Bascoul, J., and Crastes de Paulet, A. (1982).- "Autoxidation of cholesterol fatty acid esters in solid state and in aqueous dispersion". Lipids. 17, 703-708.

Kubow, S. (1993).- "Lipid oxidation products in food and atherogenesis".- Nut. Rev. 51, 33-40.

Kumar, N., and Singhal, O. P. (1991).- "Cholesterol oxides and atherosclerosis. A review". J. Sci. Food Agric. 55, 497-510.

Kushuhara, H., Shimada, O., and Inui, J. (1992).- "Effect of 25-hydroxycholesterol on cholesterol ester formation in Caco-2 cells".- Lipids 27, 478-480.

Lachance, P. A., Zeina, B. S., and Jeong, W. S. (2001). "Antioxidants: an integrative approach".- Nutrition 17, 835-842.

Lampi, A. M., Kataja, L., Kamal-Eldin, A., and Vieno, P. (1999).- "Antioxidant activity of alpha- and gamma-tocopherols in the oxidation of rape seed oil triacylglycerols".- J. Am. Oil Chem. Soc. 76, 749-755.

Lee, J. H., Shoeman, D. W., Kim, S. S., and Csallany, A. S. (1977).- "The effect of superoxide anion in the production of seven major cholesterol oxidation products in aprotic and protic conditions".- Int. J. Food Sci. Nutr. 48, 151-159.

Lehmann, J. M., Kliewer, S. A., and Moore, L. B. (1997)."Activation of nuclear receptor LXR by oxysterols defines a new hormone response pathway".- J. Biol. Chem. 272, 3137-3140.

Leland, L., S., and Johnson, B. (1989).- "Biological activities of oxysterols".- Free Rad. Biol. Med. 7, 285-332.

Leonarduzzi, G., Sottero, B., and Galli, G. (2002).-“Oxidized products of cholesterol: dietary and metabolic origin, and proatherosclerotic effects (review)".- J. Nutr. Biochem. 13, 700-710.

Li, S., Cherian, S., Ahn, D., Hardin, R., and Sim, J. (1996)."Storage, heating, and tocopherols affect cholesterol oxide formation in food oils".- J. Agric. Food Chem. 44, 3830-3834.

Lichtenstein, A. H., and Brecher, P. (1983).- "Esterification of cholesterol and 25-hydroxycholesterol by rat liver microsomes".- Biochim. Biophys. Acta 751, 340-348.
Lin, C. Y., and Morel, D. W. (1996).-" "Esterification of oxysterols in human serum: effects on distribution and cellular uptake".- J. Lipid Res. 37, 168-178.

Linseisen, J., Hoffmann, J., Riedl, J., and Wolfram, G. (1998).- "Effect of a single oral dose of antioxidant mixture (vitamin $\mathrm{E}$, and carotenoids) on the formation of cholesterol oxidation products after ex vivo LDL oxidation in humans". Eur. J. Med. Res. 3, 5-12.

Linseisen, J., and Wolfram, G. (1998 $\left.{ }^{\mathrm{a}}\right)$.- "Absorption of cholesterol oxidation products from ordinary foodstuff in humans". Ann. Nutr. Metab. 42, 221-230.

Lund, E., and Björkhem, I. (1995).-"Role of oxysterols in the regulation of cholesterol homeostasis: a critical review".- Acc. Chem. Res. 28, 241-249.

Luu, B., and Moog, C. (1991).-"Oxysterols: biological activities, physicochemical studies".- Biochimie 73, 1317-1320.

Maerker, G. (1987).- "Cholesterol autoxidation. Current status". J. Am. Oil Chem. Soc. 64, 387-392.

Maerker, G., and Unruh, J. (1986).- "Cholesterol oxides I. Isolation and determination of some cholesterol oxidation products". J. Am. Oil Chem. Soc. 3, 767-770.

Missler, S. R., Waisilchuk, B. A., and Merritt, C. (1985)."Separation and identification of cholesterol oxidation products in dried egg preparations".- J. Food Sci. 50, 595-598.

Morgan, J. N., and Armstrong, D. J. (1992).- "Quantification of cholesterol oxidation products in egg yolk powder spray-dried with direct heating". J. Food Sci. 57, 43-45.

Morel, D., and Lin, C. Y. (1996).- "Cellular biochemistry of oxysterols derived from the diet or oxidation in vivo". Nutr. Biochem. 7, 495-506.

Nieto, S., Garrido, A., Sanhueza, J., Loyola, L., Morales, G., Leighton, F., and Valenzuela, A. (1993). "Flavonoids as stabilizers of fish oil: An alternative to the use of synthetic antioxidants". J. Am. Oil Chem. Soc. 70, 773-778.

Nourooz-Zadeh, J., and Appelqvist, L. A. (1988)."Cholesterol oxides in Swedish foods and food ingredients: milk powder products". J. Food Sci. 53, 74-80.

Okamura, N., Haraguchi, H., Hashimoto, K., Yagi, A. (1994).- "Flavonoids in Rosmarinus Officinalis leaves".- Phytochemistry 37, 1463-1466.

Osada, K., Kodama, T., Yamada, K., and Sugano, M. (1993).- "Oxidation of cholesterol by heating". J. Agric. Food Chem. 41, 1198-2002.

Park, S. W., and Addis, P. B. (1985).- "HPLC determination of C-7 oxidized cholesterol derivatives in foods".- J. Food Sci. 50, 1437-1441

Park, S. W., and Addis, P. B. $\left(1985^{\mathrm{a}}\right)$.- "Capillary column gas-liquid chromatography resolution of oxidized cholesterol derivatives". Anal. Biochem. 149, 275-283.

Park, S. W., and Addis, P. B. (1986).- "Identification and quantitative estimation of oxidized cholesterol derivatives in heated tallow".- J. Agric. Food Chem. 34, 653-659.

Park, S. W., and Addis, P. B. (1992).- "Methods of analysis of cholesterol oxides".- In: Biological effects of cholesterol oxides. Peng, S. K., and Morin, R., Eds. CRC Press, Boca Raton, Chapter 3, pp 33-69.

Paniangvait, P., King, A., Jones, A. D., and German, B. G. (1995).-"Cholesterol oxides in foods of animal origin".J. Food Sci. 60, 1159-1174.

Peng, S. K., Taylor, C. B., Hill, J. C., and Morin, R. J. (1985)."Cholesterol oxidation derivatives and arterial endotelial damage".- Atherosclerosis 41: 395-402.

Pokorny, J. (1991).- "Natural antioxidants for food use".Trends Food Sci. Technol. 2, 223-226. 
Robak, J., and Gryglewski, R. (1988).- "Flavonoids are scavengers of superoxide radical". Biochem. Pharmacol. 37, 837-841.

Robins, S. J., and Brunengraber, H. (1982).- "Origin of biliary cholesterol and lecithin in the rat: contribution of new synthesis and preformed hepatic stores". J. Lipid Res. 23, 604-608.

Robins, S. J., and Fasulo, J. (1997).- "High density lipoproteins, but not other lipoproteins, provide a vehicle for sterol transport to bile". J. Clin. Invest. 99, 380-384.

Rong, J. X., Shen, L., Chang, Y. H., Richters, A., Hodis, H., and Sevanian, A. (1999).-" "Cholesterol oxidation products induce vascular foam cell lesion formation in hypercholesterolemic New Zealand white rabbits".Arterioscler. Thromb. Vasc. Biol. 19, 2179-2188.

Roux, C., Wolf, C., Mulliez, N., Gaoua, W., Cormier, V., Chevy, F., and Citadelle, D. (2000).-"Role of cholesterol in embryonic development".- $A m$. J. Clin. Nutr. 71,(suppl) 1270S-1279S.

Sander, B. D., Addis, P. B., Park, S. W., and Smith, D. E. (1989).-"Quantification of cholesterol oxidation products in a variety of foods".- J. Food Protect. 52, 109-114.

Saucier, S. E., Kandutsch, A. A., Taylor, F. R., Spencer, T. A., Phirwa, S., and Gayen, A. K. (1985).- "Identification of regulatory oxysterols, 24(S), 25-epoxycholesterol and 25-hydroxycholesterol, in cultured fibroblasts".- J. Biol. Chem. 260, 14571-14579.

Schroepfer, G. J. (2000).-"Oxysterols: Modulators of cholesterol metabolism and other process".- Physiol. Rev. 80: 361-563.

Sevanian, A., and McLeod, L. L. (1987).- "Cholesterol autoxidation in phospholipid membrane bilayers".Lipids 22, 627-636.

Shozen, K., Oshima, T., Ushio, H., Takigushi, A., and Koizumi, C. (1997).- "Effects of antioxidants and packing on cholesterol oxidation in processed anchovy during storage". Food Sci. Technol-Lebensmittel Wissenschaft \& Technologie 30, 2-8.

Smith, L.(1996).- "Review of progress in sterol oxidation". Lipids 31, 453-438.

Spector, A. A., and Yorek, M. A. (1985).-- "Membrane lipid composition and cellular function".- J. Lipid Res. 26, 1015-1035.

Staprans, I., Pan, X. M., Rapp, J. H., and Feingold, K.B. (1998).- "Oxidized cholesterol in the diet accelerates the development of aortic atherosclerosis in cholesterol-fed rabbits". Arterioscler. Throm. Vasc. Biol. 18, 977-983.

Streuli, R. A., Chung, J. A., Scanu, A. M., and Yachnin, S. (1981).- "Serum lipoproteins modulate oxygenated sterol insertion into human red cell membranes".Science 212, 1294-1296.

Tanaka, R. D., Edwards, P. A., Lan, S., and Fogelman, A. M. (1983).-"Regulation of 3-hydroxy-3-methylglutaryl coenzyme A reductase activity in avian myeloblasts. Mode of action of 25-hydroxycholesterol".- J. Biol. Chem. 258, 13331-13339.

Tuckey, R. C. (1992).- "Cholesterol side-chain cleavage by mitochondria from the human placenta. Studies using hydroxycholesterols as substrates".- J. Steroid Biochem. Mol. Biol. 42, 833-890.

Valenzuela, A. (2002).-"Natural antioxidants: from food safety to health benefits".- Biotechnol. Feed Ind. 18: 323-332.

Valenzuela, A., and Nieto, S. (1996).- "Natural and synthetic antioxidants: food quality protectors".Grasas \& Aceites 47, 186-196.

Valenzuela, A., Sanhueza, J., and Nieto, S. (2002).- "Effect of synthetic antioxidants on cholesterol stability during the thermal-induced oxidation of a polyunsaturated vegetable oil". J. Am. Oil Chem. Soc. 79, 325-328.

Valenzuela, A., Sanhueza, J., and Nieto, S. (2002 $\left.{ }^{\mathrm{a}}\right)$."Differential inhibitory effect of $\alpha-, \beta-, \quad \gamma-$, and $\delta$-tocopherols, on the metal-induced oxidation of cholesterol in unilamellar phospholipid-cholesterol liposomes". J. Food Sci. 67, 2051-2055.

Valenzuela, A., Sanhueza, J., and Nieto, S. (2003).-"Natural antioxidants in functional foods: from food safety to health benefits".- Grasas \& Aceites, 54, 295-303.

Valenzuela, A., Sanhueza, J., Alonso, P., Corbari, A., and Nieto, S. (2004).- "Inhibitory action of conventional food-grade natural antioxidants and of natural antioxidants of new development on the thermal-induced oxidation of cholesterol".- Int. J. Food Sci. Nutr. 55, 155-162.

Van de Bovenkamp, P., Kosmeijer-Schuil, T. G., Katan, M. B. (1988).- "Quantification of oxysterols in Dutch foods: eggs products and mixed diets".- Lipids 23, 1079-1085.

Wu, J. W., Lee, M. H., HO, C. T., and Chang, S. S. (1982)."Elucidation of the chemical structure of natural antioxidants isolated from rosemary".- J. Am. Oil Chem. Soc. 59, 339-345.

Yeagle, P. L. (1985).-"Cholesterol in the cell membrane".Biochim. Biophys. Acta 822, 267-287.

Yoshida, H., Kajimoto, G., and Emura, S. (1993)."Antioxidant effects of d-tocopherols at different concentrations in oils during microwave heating".- $J$. Am. Oil Chem. Soc. 70, 989-995.

Zhang, W. B., Addis, P. B., and Krick, T. P. (1992)."Quantification of 5-alpha cholestane-3 beta, 5, 6-triol and other cholesterol oxidation products in fast food French fried potatoes". J. Food Sci. 57, 716-718.

Recibido: Junio 2003 Aceptado: Octubre 2003 